\title{
Technology Access, Technical Assistance, and Disparities in Inpatient Portal Use
}

\author{
Lisa V. Grossman ${ }^{1}$ Ruth M. Masterson Creber ${ }^{2}$ Jessica S. Ancker ${ }^{2}$ Beatriz Ryan ${ }^{3}$ \\ Fernanda Polubriaginof ${ }^{3}$ Min Qian ${ }^{4}$ Irma Alarcon ${ }^{1}$ Susan Restaino ${ }^{5}$ Suzanne Bakken ${ }^{1}$ \\ George Hripcsak ${ }^{1}$ David K. Vawdrey ${ }^{1,3}$
}

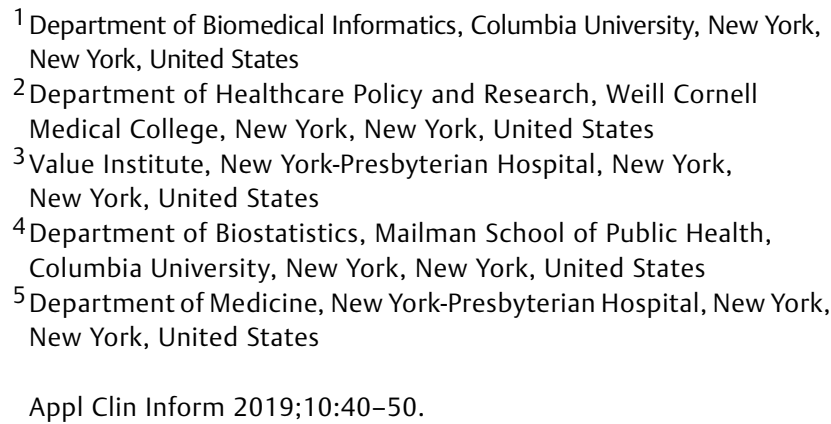

Address for correspondence Lisa V. Grossman, Department of Biomedical Informatics, Columbia University, 622 West 168th Street, PH-20, New York, NY 10032, United States (e-mail: lvg2104@cumc.columbia.edu).

\section{Abstract}

Keywords

- health records

- patient portals

- informatics

- patient engagement
Background Disadvantaged populations, including minorities and the elderly, use patient portals less often than relatively more advantaged populations. Limited access to and experience with technology contribute to these disparities. Free access to devices, the Internet, and technical assistance may eliminate disparities in portal use. Objective To examine predictors of frequent versus infrequent portal use among hospitalized patients who received free access to an iPad, the Internet, and technical assistance.

Materials and Methods This subgroup analysis includes 146 intervention-arm participants from a pragmatic randomized controlled trial of an inpatient portal. The participants received free access to an iPad and inpatient portal while hospitalized on medical and surgical cardiac units, together with hands-on help using them. We used logistic regression to identify characteristics predictive of frequent use.

Results More technology experience (adjusted odds ratio $[\mathrm{OR}]=5.39, p=0.049$ ), less severe illness (adjusted $\mathrm{OR}=2.07, p=0.077$ ), and private insurance (adjusted $\mathrm{OR}=2.25, p=0.043$ ) predicted frequent use, with a predictive performance (area under the curve) of $65.6 \%$. No significant differences in age, gender, race, ethnicity, level of education, employment status, or patient activation existed between the frequent and infrequent users in bivariate analyses. Significantly more frequent users noticed medical errors during their hospital stay.

Discussion and Conclusion Portal use was not associated with several sociodemographic characteristics previously found to limit use in the inpatient setting. However, limited technology experience and high illness severity were still barriers to frequent use. Future work should explore additional strategies, such as enrolling health care proxies and improving usability, to reduce potential disparities in portal use. received

August 17, 2018

accepted after revision

November 22, 2018 (c) 2019 Georg Thieme Verlag KG Stuttgart · New York
DOI https://doi.org/

$10.1055 / \mathrm{s}-0038-1676971$. ISSN 1869-0327. 


\section{Background and Significance}

The percentage of health care organizations offering online patient portals rose from $43 \%$ in 2013 to $92 \%$ in $2015 .^{1-3}$ The rapid adoption of portals reflects health care organizations' increasing focus on patient engagement, person-centered care, and shared decision making. ${ }^{4,5}$ In 2016, a national survey found that hospital leaders view portals as the most effective tool to engage patients with their health care. ${ }^{6}$ The federal Meaningful Use program has driven portal adoption, by incentivizing organizations to provide patients with electronic access to their health information. ${ }^{7}$ As portals become increasingly available, more patients use them..$^{8-11}$ In the United States, the rate of self-reported portal use rose from $17 \%$ in 2014 to $28 \%$ in $2017 .^{12,13}$

The increasing popularity of portals and their potential utility to hospitalized patients has motivated some organizations to adopt inpatient portals, or patient portals accessed in the hospital setting. ${ }^{14-19}$ Vendors now offer portals intended specifically for in-hospital use, such as MyChart Bedside from Epic Systems Corporation. ${ }^{20}$ Institutions use inpatient portals to address patients' information needs, engage patients in decision making, facilitate patient-provider communication, improve transparency, provide health education, increase patient safety, and enable transitions of care. $^{14,15}$ Research suggests that inpatient portals may improve patient safety and satisfaction. ${ }^{21-26}$ Inpatient portals empower patients to report safety concerns, facilitate patient recognition of errors, improve patients' perceptions of safety and quality, and fulfill patients' information needs.

Many studies report that disadvantaged populations such as racial and ethnic minorities and low income, low literacy, elderly, and disabled persons use patient portals less often, in both outpatient and inpatient settings. ${ }^{27-36}$ Research suggests that limited access to and experience with technology, as well as limited assistance with the portal, contribute to disparities in portal use. ${ }^{27,31,37-41}$ According to the Pew Research Center, in 2018, 23\% of Americans do not own a smartphone, ${ }^{42}$ and $11 \%$ never use the Internet. ${ }^{43}$ Disadvantaged populations experience a higher burden of disease, and relatively low portal use among disadvantaged groups may worsen existing health disparities. ${ }^{41,44}$ As portals gain in popularity, identifying strategies to reduce disparities in use is essential, to ensure portals benefit all populations. ${ }^{41}$

To date, interventions designed to reduce disparities in portal use include universal access policies, ${ }^{44}$ caregiver enrollment, ${ }^{37}$ and computer literacy training. ${ }^{45,46}$ Intervention success is hampered by (1) difficulty reaching disadvantaged populations for enrollment and training, (2) limited technology access in disadvantaged populations, and (3) difficulty achieving scale. The inpatient setting offers unique opportunities to overcome such limitations. Hospitalized patients may be more easily reached with hands-on interventions, and represent the sickest and most vulnerable population. Because portals improve access to information, engaging hospitalized patients with portals should have farreaching consequences such as improved patient safety and trust. $^{21,47}$
We conducted a pragmatic randomized controlled trial (RCT) of a locally developed inpatient portal delivered to hospitalized patients. ${ }^{16,48}$ In the trial, we implemented strategies to ensure every intervention-arm participant could use the portal. Specifically, portal users received (1) free access to hospital-provided iPads and the Internet, (2) assistance in establishing their portal account, (3) basic training on how to use the portal, and (4) regular troubleshooting. In this subgroup analysis, we examine characteristics associated with frequent and infrequent portal use in the intervention arm, specifically (1) health-equity-relevant characteristics such as age, gender, race, ethnicity, socioeconomic status, health literacy, technology experience, and illness severity, (2) engagement and satisfaction with health care, and (3) perceived usefulness and ease-of-use of both the iPad and portal.

\section{Materials and Methods}

\section{Study Design}

The RCT is registered with ClinicalTrials.gov (NCT01970852). The protocol and primary results have been published separately. ${ }^{16,48}$ Between March 2014 and May 2017, patients at a large urban hospital were recruited and randomized into three arms: (1) usual care, (2) iPad with general Internet access, (3) iPad with inpatient portal. In the RCT, the primary outcome was change in patient activation from baseline. Patient activation is an individual's knowledge, skills, and confidence in managing their health and health care. Secondary outcomes included (1) potential medical errors that patients noticed during their hospital stay, (2) patient satisfaction and engagement with health care, (3) perceived usefulness and ease-of-use of the iPad and portal, and (4) medical record inaccuracies that patients identified using the portal. Participants completed a baseline questionnaire to assess demographics, socioeconomic status, health literacy, patient activation, and technology experience. Three to five days later, participants completed a follow-up questionnaire to assess primary and secondary outcomes. For this paper, we conducted a retrospective subgroup analysis of participants in the third arm, hereby called portal users. The Columbia University Institutional Review Board approved the trial and all patients provided informed consent.

\section{Intervention}

We designed and developed an inpatient portal that provides hospitalized patients with real-time access to their clinical data, sourced directly from the electronic health record. A comprehensive description of the portal has been published $^{16}$ and is summarized here. Portal features included (1) names, photos, and roles of care team members, (2) medications, (3) allergies, (4) diagnostic laboratory test orders and results, (5) current diet, (6) vital signs, (7) glucose levels, (8) weights, (9) patient-reported pain levels, (10) patient-generated messages to the portal team and hospital staff, (11) written and video educational materials on medications and tests, (12) portal navigation tutorials, and (13) Spanish translation ( - Fig. 1). User actions were recorded in a detailed system use log. 


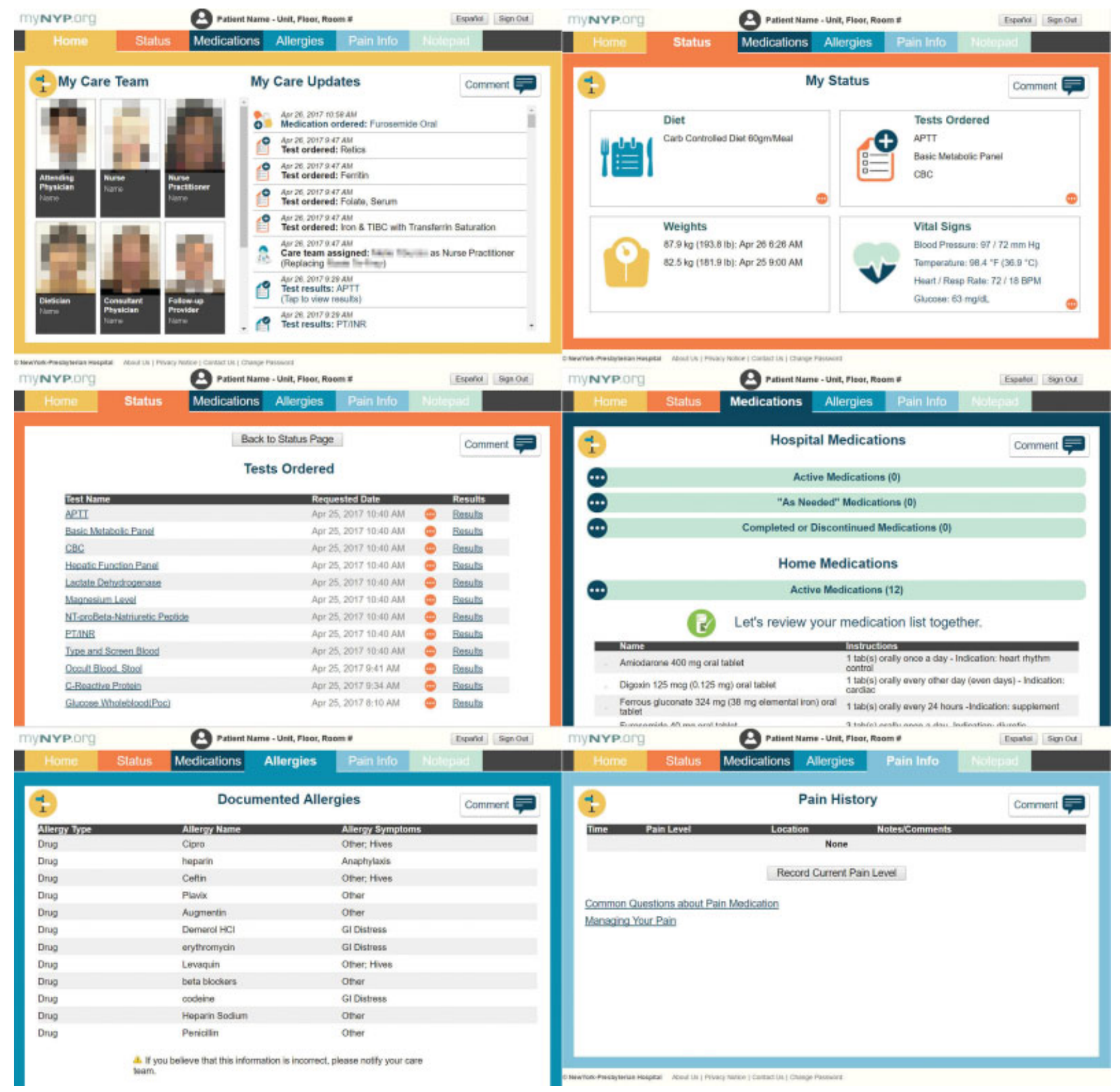

Fig. 1 Screenshots of the inpatient portal.

\section{Participants}

Participants included adult patients aged 18 years or older who spoke English or Spanish, admitted to one of two medical and surgical cardiac units at an urban academic medical center. We excluded patients with a Mini Mental Status Examination score less than 9, patients placed in contact isolation, patients involved in another research study, patients unable to provide written informed consent, and patients already admitted for more than 2 weeks. The exclusion criteria were limited to improve generalizability.

\section{Recruitment}

The research coordinators identified new admissions from the electronic health record, confirmed eligibility, obtained written informed consent, and administered the question- naires. The coordinators enrolled users in the portal system, and provided their unique username and password. Each intervention-arm participant underwent a brief training session to familiarize them with the iPad and portal as appropriate to their level of technology experience. Training included basic iPad gestures (tapping, scrolling, and zooming), signing into the portal, and an overview of portal features. Portal users also received a handout with instructions (-Fig. 2). The coordinators visited participants daily to address potential issues with the iPad, Internet, or portal, such as difficulty signing in.

\section{Measures and Data Sources}

The baseline and follow-up questionnaires have been previously described. ${ }^{16}$ To assess health literacy, we used Chew 


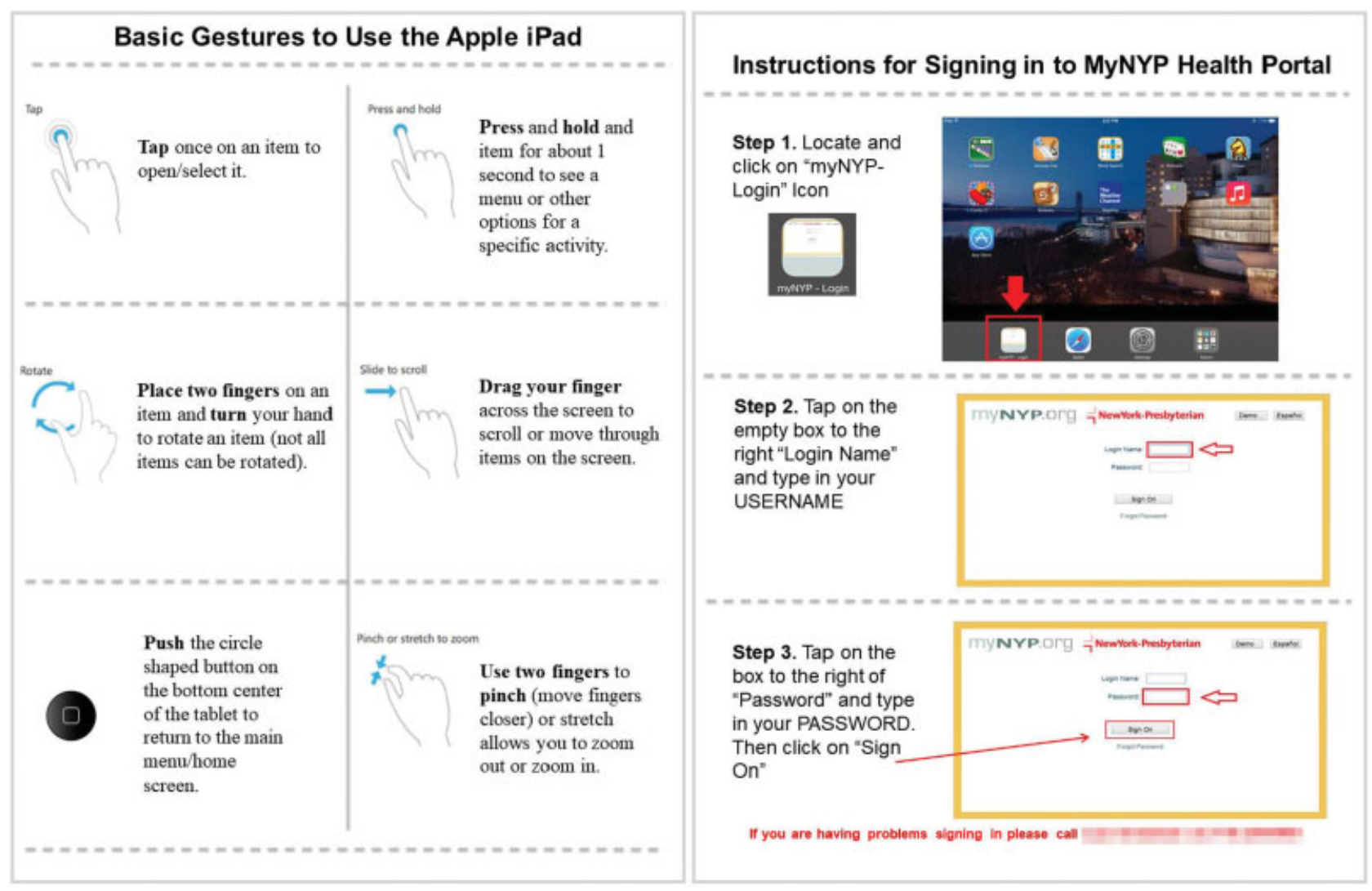

Fig. 2 Technology assistance handout.

and colleagues' health literacy screening questions. ${ }^{49}$ To assess patient activation, we used the 13-item Patient Activation Measure (PAM-13). ${ }^{50-56}$ Our team has previously validated the PAM-13 in the inpatient setting. ${ }^{57}$ To assess patient-identified medical errors, we asked patients to describe and categorize errors they noticed while enrolled in the trial. To assess patient satisfaction, patient engagement, perceived usefulness, and perceived ease-of-use, we adapted the Telemedicine Satisfaction and Usefulness Questionnaire. ${ }^{58}$

We obtained information on unit and hospital demographics, insurance type, mailing address, diagnoses, length of hospital stay, All Patient Refined Diagnosis Related Group (APR-DRG) Severity of Illness, ${ }^{59}$ and APR-DRG Risk of Mortality ${ }^{60}$ from our institution's clinical data warehouse. APRDRG Severity of Illness is defined as "the extent of organ system loss of function or physiologic decompensation," and Risk of Mortality is defined as "the likelihood of dying." The APR-DRG categorizes both Severity of Illness and Risk of Mortality as minor (level 1), moderate (level 2), major (level 3 ), or extreme (level 4). We used diagnosis information to calculate each participant's Charlson Comorbidity Index, ${ }^{61}$ which predicts 10 -year mortality. We geocoded participant mailing addresses to obtain their census tracts, which enabled linkage with the 2016 Centers for Disease Control and Prevention (CDC) Social Vulnerability Index, ${ }^{62}$ an overall score for census tracts based on social determinants. We excluded post office boxes since these addresses may not reflect the actual residence.

\section{Statistical Analyses}

To categorize portal use as frequent or infrequent for each participant, a composite use variable was utilized. ${ }^{63}$ We utilized the composite variable to capture multiple aspects of patients' portal use and provide the best overall assessment. Specifically, participants' portal use was classified as frequent if it exceeded thresholds in four out of four metrics: (1) total number of logins, (2) logins per day, (3) total minutes using the portal, and (4) minutes using the portal per day. The thresholds were (1) two or more logins total, (2) one or more logins per day on average, (3) 50 minutes using the portal total, and (4) 20 minutes using the portal per day on average. We determined thresholds based on logical breaks in the data, since descriptive analyses found bimodal or multimodal distributions for all four metrics.

After portal users were classified into subgroups, we conducted bivariate analyses to assess whether each baseline characteristic or outcome differed between frequent and infrequent users. Nominal variables were compared using chi-squared tests or Fisher's exact tests with Monte Carlo approximation, while ordinal and numerical variables were compared using Wilcoxon rank-sum tests.

We further used multivariable binomial logistic regression to examine the relationship between baseline characteristics and portal use (frequent vs. infrequent). First, we constructed a preliminary main effect model using all independent variables where $p<0.25$ in bivariate analyses. ${ }^{64}$ Then, we used the R package glmulti ${ }^{65}$ to perform exhaustive 
automated model selection using Akaike information criteria (AIC) for model comparison. glmulti builds all possible unique models and selects the highest quality one as per AIC to reward goodness-of-fit, penalize overfitting, and avoid collinearity. We performed preliminary experiments testing interaction terms and regularization approaches, but ultimately excluded them to prevent overfitting and support parsimony in model selection. We assessed predictive ability using area under the ROC curve (AUC), calculated by averaging results from 1,000 random five-fold cross-validation cycles to improve the metric's stability. All analyses were conducted in R version 3.3.3 and SAS version 9.4.

\section{Results}

Of the 478 individuals assessed for eligibility, 23 did not meet the inclusion criteria and 1 declined to participate. We enrolled the remaining 454 individuals, 155 of whom were randomized to the portal arm. Nine portal users did not complete the trial, including 4 who withdrew consent, 3 deceased, and 2 lost to follow-up. Of the 146 portal users who completed the trial, 93 (63.7\%) met the criteria for frequent use of the inpatient portal, and the remaining 53 (36.3\%) had infrequent use. Among infrequent users, 25 (47\%) never used the portal. A comparison of baseline characteristics between frequent and infrequent user groups is presented in - Table 1. Overall, portal users had an average age of 56 years (range: 22-89). Portal users were 16.0\% Black, 22.1\% Latino, and $8.3 \%$ preferred Spanish as a primary language. Portal users were representative of our institution's hospitalized population based on gender, race, and ethnicity, but were slightly younger (- Supplementary Table 1, available in the online version).

No significant differences in age, gender, race, ethnicity, level of education, employment status, or baseline patient activation existed between the frequent and infrequent users. As shown in - Table 1, frequent use was associated with more technology experience (indicated by Internet access at home and having an email address), higher socioeconomic status (indicated by insurance type and household income), and less severe illness (as measured by the Charlson Comorbidity Index, Severity of Illness level, and Risk of Mortality level).

Insurance type, Internet access at home, and Severity of Illness level were included in the multivariable logistic regression model ( - Table 2 ), reflecting portal users' socioeconomic status, technology experience, and illness severity, respectively. Predictive performance (AUC) for the model

Table 1 Baseline characteristics

\begin{tabular}{|c|c|c|c|c|}
\hline \multirow[t]{2}{*}{ Variable } & \multirow{2}{*}{$\begin{array}{l}\text { All users, } \\
n=146\end{array}$} & \multicolumn{2}{|c|}{ Subgroup analysis } & \multirow[t]{2}{*}{$p$-Value } \\
\hline & & $\begin{array}{l}\text { Infrequent use, } \\
n=53\end{array}$ & $\begin{array}{l}\text { Frequent use, } \\
n=93\end{array}$ & \\
\hline \multicolumn{5}{|l|}{ Demographics } \\
\hline Age (mean, SD) & $56.3 \pm 15.2$ & $58.6 \pm 16.6$ & $55.0 \pm 14.3$ & 0.140 \\
\hline Female sex $(n, \%)$ & $59(40.4)$ & $18(34.0)$ & $41(44.1)$ & 0.231 \\
\hline \multicolumn{5}{|l|}{ Race $(n, \%)$} \\
\hline Asian or Pacific Islander & $4(2.8)$ & $2(3.8)$ & $2(2.2)$ & \multirow[t]{5}{*}{0.064} \\
\hline Black or African American & $23(16.0)$ & $13(24.5)$ & $10(11.0)$ & \\
\hline Multi-race & $4(2.8)$ & $3(5.7)$ & $1(1.1)$ & \\
\hline Other & $29(20.1)$ & $8(15.1)$ & $21(23.1)$ & \\
\hline White & $84(58.3)$ & 27 (50.9) & $57(62.6)$ & \\
\hline Hispanic, Latino, or Spanish origin (n, \%) & $32(22.1)$ & 10 (18.9) & $22(23.9)$ & 0.481 \\
\hline \multicolumn{5}{|l|}{ Country of origin $(n, \%)$} \\
\hline Dominican Republic or Puerto Rico & $10(6.9)$ & $3(5.7)$ & $7(7.6)$ & \multirow[t]{3}{*}{0.183} \\
\hline United States & $108(74.5)$ & $36(67.9)$ & $72(78.3)$ & \\
\hline Other & $27(18.6)$ & $14(26.4)$ & $13(14.1)$ & \\
\hline Spanish as preferred language $(n, \%)$ & $12(8.3)$ & $5(9.6)$ & $7(7.6)$ & 0.757 \\
\hline \multicolumn{5}{|l|}{ Socioeconomic status } \\
\hline Social vulnerability index (mean, SD) & $0.54 \pm 0.32$ & $0.58 \pm 0.33$ & $0.51 \pm 0.31$ & 0.222 \\
\hline \multicolumn{5}{|l|}{ Education $(n, \%)$} \\
\hline$<$ High school graduate or GED & $12(8.3)$ & $4(7.5)$ & $8(8.7)$ & \multirow[t]{4}{*}{0.419} \\
\hline High school graduate or GED & $24(16.6)$ & $8(15.1)$ & $16(17.4)$ & \\
\hline Associate's degree, technical school, some college & $53(36.6)$ & $24(45.3)$ & $29(31.5)$ & \\
\hline College graduate or higher & $56(38.6)$ & $17(32.1)$ & $39(42.4)$ & \\
\hline
\end{tabular}


Table 1 (Continued)

\begin{tabular}{|c|c|c|c|c|}
\hline \multirow[t]{2}{*}{ Variable } & \multirow{2}{*}{$\begin{array}{l}\text { All users, } \\
n=146\end{array}$} & \multicolumn{2}{|c|}{ Subgroup analysis } & \multirow[t]{2}{*}{$p$-Value } \\
\hline & & $\begin{array}{l}\text { Infrequent use, } \\
n=53\end{array}$ & $\begin{array}{l}\text { Frequent use, } \\
n=93\end{array}$ & \\
\hline \multicolumn{5}{|l|}{ Employment status ( $n, \%)$} \\
\hline Employed & $79(55.6)$ & $23(44.2)$ & $56(62.2)$ & \multirow[t]{3}{*}{0.054} \\
\hline Unemployed & $29(20.4)$ & $11(21.2)$ & $18(20.0)$ & \\
\hline Retired & $34(23.9)$ & $18(34.6)$ & $16(17.8)$ & \\
\hline \multicolumn{5}{|l|}{ Insurance type (n, \%) } \\
\hline Public (Medicare or Medicaid) only & $28(19.3)$ & $13(25.0)$ & $15(16.1)$ & \multirow[t]{4}{*}{$0.013^{\mathrm{a}}$} \\
\hline Public plus private supplement & $51(35.2)$ & $24(46.2)$ & $27(29.0)$ & \\
\hline Private or commercial only & $54(37.2)$ & $14(26.9)$ & $40(43.0)$ & \\
\hline Self-pay ${ }^{b}$ & $12(8.3)$ & $1(1.9)$ & $11(11.8)$ & \\
\hline \multicolumn{5}{|l|}{ Annual household income $(n, \%)$} \\
\hline Less than 15,000 USD & $11(14.5)$ & $2(8.3)$ & $9(17.3)$ & \multirow[t]{4}{*}{$0.010^{\mathrm{a}}$} \\
\hline $15,000-50,000$ USD & $17(22.4)$ & $11(45.8)$ & $6(11.5)$ & \\
\hline $50,000-100,000$ USD & $19(25.0)$ & $5(20.8 \%)$ & $14(26.9)$ & \\
\hline More than 100,000 USD & $29(38.2)$ & $6(25.0)$ & $23(44.2)$ & \\
\hline Inadequate health literacy $(n, \%)$ & $55(37.7)$ & $22(41.5)$ & $33(35.5)$ & 0.470 \\
\hline \multicolumn{5}{|l|}{ Technology experience } \\
\hline Can access desktop, laptop, or tablet at home $(n, \%)$ & $136(93.2)$ & $48(90.6)$ & $88(94.6)$ & 0.497 \\
\hline Can access the Internet at home $(n, \%)$ & $133(91.1)$ & $42(79.2)$ & $91(97.8)$ & $<0.001^{\mathrm{a}}$ \\
\hline \multicolumn{5}{|l|}{ Daily Internet use in past 30 days $(n, \%)$} \\
\hline$<1$ hour & $41(28.1)$ & $18(34.0)$ & $23(24.7)$ & \multirow[t]{3}{*}{0.312} \\
\hline $1-3$ hours & $47(32.2)$ & $18(34.0)$ & $29(31.2)$ & \\
\hline$>3$ hours & $58(39.7)$ & $17(32.1)$ & $41(44.1)$ & \\
\hline Has email address $(n, \%)$ & $128(87.7)$ & $41(77.4)$ & $87(93.5)$ & $0.004^{\mathrm{a}}$ \\
\hline Looks up health information online $(n, \%)$ & $121(82.9)$ & $42(79.2)$ & $79(84.9)$ & 0.379 \\
\hline \multicolumn{5}{|l|}{ Illness severity } \\
\hline Charlson Comorbidity Index (mean, SD) & $2.4 \pm 2.0$ & $2.8 \pm 2.1$ & $2.1 \pm 1.9$ & $0.036^{\mathrm{a}}$ \\
\hline Severity of Illness level (mean, SD) & $2.7 \pm 1.0$ & $2.9 \pm 1.0$ & $2.6 \pm 0.9$ & $0.020^{\mathrm{a}}$ \\
\hline Risk of Mortality level (mean, SD) & $2.4 \pm 1.0$ & $2.6 \pm 0.9$ & $2.3 \pm 1.0$ & $0.028^{a}$ \\
\hline Length of hospital stay, days (mean, SD) & $11.9 \pm 14.7$ & $14.7 \pm 14.7$ & $10.4 \pm 14.5$ & $0.005^{\mathrm{a}}$ \\
\hline \multicolumn{5}{|l|}{ Patient activation } \\
\hline PAM score, pre (mean, SD) & $69.9 \pm 14.6$ & $71.7 \pm 14.6$ & $68.9 \pm 14.7$ & 0.306 \\
\hline
\end{tabular}

Abbreviations: GED, General Education Diploma; $n$, number; PAM, Patient Activation Measure; SD, standard deviation; USD, United States dollars. Note: Categorical variables reported as $n(\%)$, and $p$-values calculated using chi-squared tests or Fisher's exact tests with Monte Carlo approximation. Continuous variables reported as mean \pm SD, and $p$-values calculated using Wilcoxon rank-sum tests. Percentages exclude missing data.

${ }^{\mathrm{a}}$ Significant at $p=0.05$.

bIn this clinical setting, "self-pay" reflects high-income patients who pay out-of-pocket for elective care.

was $65.6 \%$, indicating moderate predictive ability for frequent versus infrequent portal use.

An exploratory analysis of outcomes from the RCT, comparing frequent and infrequent users, is presented in -Table 3. No significant differences in patient activation, satisfaction, and engagement existed between frequent and infrequent users. A significantly greater percentage of frequent users reported using the iPad to look up health information online (97 vs. $76 \% ; p<0.001$ ).
A greater percentage of frequent users noticed potential medical errors during their hospital stay (22 vs. 4\%; $p=0.010)$. About half (51\%) of potential medical errors related to medication dosage or administration. Other potential errors related to laboratory tests or procedures (21\%), pain control $(9 \%)$, diet $(8 \%)$, allergies $(6 \%)$, diagnosis $(<2 \%)$, hospital-acquired infections ( $<2 \%)$, and sanitation $(<2 \%)$. A greater percentage of frequent users noticed inaccurate information in their medical record (20 vs. $9 \%, p=0.133$ ), 
Table 2 Predictors of frequent acute care portal use

\begin{tabular}{|l|l|l|}
\hline Variable & Adjusted OR (95\% Cl) & $p$-Value \\
\hline $\begin{array}{l}\text { Private insurance or } \\
\text { self-pay (vs. public) }\end{array}$ & $2.25(1.03-5.02)$ & 0.043 \\
\hline $\begin{array}{l}\text { Can access the Internet } \\
\text { at home (vs. cannot) }\end{array}$ & $5.39(1.15-38.94)$ & 0.049 \\
\hline $\begin{array}{l}\text { Severity of illness level } \\
1 \text { or } 2 \text { (vs. 3 or 4) }\end{array}$ & $2.07(0.93-4.78)$ & 0.077 \\
\hline
\end{tabular}

Abbreviations: $\mathrm{Cl}$, confidence interval; OR, odds ratio.

Note: We included only complete cases in our analysis, meaning we excluded 15 out of 146 portal users due to missing data values ( $n=131,47$ infrequent users and 84 frequent users).

although the difference lacked statistical significance in this trial. Overall, only $41 \%$ of portal users who noticed inaccurate information reported it to their health care provider.

\section{Discussion}

Although hospitalized patients experience high information needs, illness severity and stress due to hospitalization may obstruct their use of an inpatient portal. On the other hand, the hospital setting offers unique opportunities to promote portal use. Hospitals can offer free devices and Internet to inpatients, help set up portal accounts, and teach patients to use the portal. Such interventions may offset the barriers that contribute to disparities in portal use, in both inpatient and outpatient settings. Under the technology access and assistance conditions of our pragmatic RCT, many expected disparities were not evident. Specifically, age, gender, race, ethnicity, level of education, employment status, and patient activation were not associated with frequent use. However, more severe illness, preexisting limited technology experience, and public insurance were significantly associated with infrequent use, despite technology access and assistance.

Table 3 Outcomes

\begin{tabular}{|c|c|c|c|c|}
\hline \multirow[t]{2}{*}{ Variable } & \multirow{2}{*}{$\begin{array}{l}\text { All users, } \\
n=146\end{array}$} & \multicolumn{2}{|c|}{ Subgroup analysis } & \multirow[t]{2}{*}{$p$-Value } \\
\hline & & $\begin{array}{l}\text { Infrequent use, } \\
n=53\end{array}$ & $\begin{array}{l}\text { Frequent use, } \\
n=93\end{array}$ & \\
\hline \multicolumn{5}{|l|}{ Patient activation } \\
\hline PAM score, post & $74.3 \pm 16.0$ & $74.8 \pm 16.5$ & $74.0 \pm 15.8$ & 0.789 \\
\hline PAM score, pre-post difference & $4.4 \pm 14.4$ & $3.2 \pm 15.9$ & $5.1 \pm 13.6$ & 0.977 \\
\hline PAM score, pre-post difference $>3^{\text {a }}$ & $70(48.3 \%)$ & $26(50.0 \%)$ & $44(47.3 \%)$ & 0.756 \\
\hline \multicolumn{5}{|l|}{ Medical errors } \\
\hline I noticed medical errors while hospitalized & $21(15.9 \%)$ & $2(4.4 \%)$ & $19(21.8 \%)$ & $0.010^{\mathrm{b}}$ \\
\hline I noticed inaccurate information in my record & $20(16.5 \%)$ & $3(8.6 \%)$ & $17(19.8 \%)$ & 0.133 \\
\hline If yes, I reported the inaccuracy & $7(41.2 \%)$ & $1(50.0 \%)$ & $6(40.0 \%)$ & 1.000 \\
\hline If yes, the inaccuracy was amended & $3(60.0 \%)$ & $0(0.0 \%)$ & $3(75.0 \%)$ & 0.400 \\
\hline \multicolumn{5}{|l|}{ Patient satisfaction and engagement with care } \\
\hline Patient satisfaction and engagement with care & $4.4 \pm 0.5$ & $4.4 \pm 0.5$ & $4.4 \pm 0.5$ & - \\
\hline \multicolumn{5}{|l|}{ Perceived usefulness and ease-of-use of iPad } \\
\hline \multicolumn{5}{|l|}{ I used the iPad to ... } \\
\hline access my email & $20(14.8 \%)$ & $5(11.1 \%)$ & $15(16.7 \%)$ & 0.392 \\
\hline entertain myself & $92(68.1 \%)$ & $30(66.7 \%)$ & $62(68.9 \%)$ & 0.794 \\
\hline look up health information online & $121(89.6 \%)$ & $34(75.6 \%)$ & $87(96.7 \%)$ & $<0.001^{\mathrm{b}}$ \\
\hline The iPad is easy to use & $4.4 \pm 0.7$ & $4.1 \pm 0.8$ & $4.5 \pm 0.6$ & - \\
\hline \multicolumn{5}{|l|}{ Perceived usefulness and ease-of-use of portal } \\
\hline The portal is easy to use & $4.5 \pm 0.7$ & $4.3 \pm 0.8$ & $4.5 \pm 0.6$ & - \\
\hline The portal made it easier to contact my care team & $3.3 \pm 1.2$ & $3.4 \pm 1.2$ & $3.2 \pm 1.2$ & 0.411 \\
\hline I entered questions or comments into my portal & $32(26.4 \%)$ & $7(20.0 \%)$ & 25 (29.1\%) & 0.305 \\
\hline
\end{tabular}

Abbreviations: $n$, number; PAM, Patient Activation Measure.

Note: Categorical variables reported as $n(\%)$, and $p$-values calculated using chi-squared tests or Fisher's exact tests with Monte Carlo approximation. Continuous variables reported as mean \pm SD, and $p$-values calculated using Wilcoxon rank-sum tests. Scores based on questionnaires with Likerttype rating scales (satisfaction, ease-of-use) reported as numbers between 1 and 5 . Percentages exclude missing data.

${ }^{a}$ Studies suggest a pre-post difference greater than 3 in the PAM score is clinically significant.

bignificant at $p=0.05$. 
In the outpatient setting, research suggests that low technology literacy, alongside limited computer and Internet access, impacts outpatients' adoption of portals as well as their continued use. ${ }^{31,38-40}$ Currently, many patients access inpatient portals through hospital-provided devices, as in this RCT. However, hospital-provided devices require maintenance and disinfection, prompting some organizations to consider "bring your own device" (BYOD) options. ${ }^{14}$ Unfortunately, BYOD may exacerbate disparities in portal use, by adding the additional barriers of computer and Internet access. Therefore, organizations should consider maintaining hospital-provided device programs.

The relationship between illness severity and portal use is more complex. ${ }^{31}$ Some studies suggest that having multiple comorbidities is associated with increased portal adoption, ${ }^{66,67}$ while others indicate that poorer overall health is associated with decreased portal adoption. ${ }^{67}$ One hypothesis is that patients use portals more as their health condition worsens, until they become too sick to use it. At that point, their use declines. We studied an overall sicker population, hospitalized patients, and found that use declines as illness severity increases. These data are consistent with the hypothesis that the relationship between illness severity and portal use is parabolic.

Since disparities in use of inpatient portals exist despite technology access and assistance, health care organizations must consider additional strategies that promote equal access. One possible strategy is enrolling caregivers, such as surrogate decision makers or health care proxies. Caregivers may help patients with low technology literacy or severe illness access their information. This strategy may be of limited use among the most severely socioeconomically disadvantaged patients, whose family and caregivers may themselves have limited technology literacy. An alternative strategy is additional in-hospital training on portal use. The hospital setting offers an opportunity for patients to develop familiarity with the portal software while assistance is available. New approaches to improving usability may help reduce training needs. ${ }^{68,69}$

Despite the well-documented evidence for disparities in outpatient portal use, ${ }^{27-33}$ fewer studies have investigated potential disparities in inpatient portal use. ${ }^{34-36}$ However, this study and the existing literature indicate that disparities in use occur with inpatient portals as with outpatient ones. Given the development of products like MyChart Bedside and HealtheLife, both available in Spanish, inpatient portal availability is expected to increase rapidly in the coming years. Implementing strategies such as universal access policies, ${ }^{44}$ hospital-provided device programs, and technical assistance alongside inpatient portals will be critical to reduce disparities in use. In this study, 93 (63.7\%) patients demonstrated frequent use, meaning they logged on for over 20 minutes per day on average. These data suggest that many hospitalized patients will use portals given the opportunity, and organizations should explore strategies to ensure all populations receive and benefit from this opportunity.

Significantly more frequent users noticed medical errors during their hospital stay (22 vs. $4 \% ; p=0.01$ ). It is unclear whether the portal helped users identify medical errors, or whether noticing errors prompted portal use, or whether a third variable explains both noticing medical errors and portal use. As with medical errors, frequent users were more likely to notice inaccuracies in their medical record (20 vs. $9 \%, p=0.133$ ), although the difference lacked statistical significance. Recent research from OpenNotes found that $23 \%$ of patients who reviewed their doctor's notes identified potential safety concerns. ${ }^{70}$ Inpatient portal developers should explore methods to engage patients as partners in improving safety, and consider creating explicit protocols for reporting safety concerns through patient portals.

We did not find significant differences in patient activation between groups, although recent research suggests that standardized administration of the PAM is challenging, especially within our population. ${ }^{71}$ Previous research on whether high patient activation correlates with portal use is mixed. ${ }^{72,73}$ Hibbard and Greene, developers of the Patient Activation Measure, have reported that patients with high activation levels use portals more often. ${ }^{73}$ However, a smaller study among outpatients at our center failed to find an association between PAM score and portal use, though it did find the expected associations with education and socioeconomic status. ${ }^{72}$ Future research should further investigate how patient activation interacts with portal use.

\section{Limitations}

We conducted this trial at an urban academic medical center with an advanced informatics infrastructure, and findings may not generalize to other health care settings. Additional barriers to inpatient portal use could include (1) literacy factors such as numeracy or text literacy, (2) portal factors such as usability, utility, and cost, (3) attitudinal factors such as motivation or concerns about privacy, and (4) patient-provider relationship factors such as communication and trust. ${ }^{31}$ Future work should explore these potential barriers and their impact on inpatient portal use. Our study excluded visually, physically, and cognitively impaired patients, despite evidence that these patient populations experience a higher burden of disease. Future work should explore strategies to engage persons with disabilities in inpatient portals. Finally, creating standardized methods to assess composite portal use remains an urgent problem, especially since individual metrics do not reflect actual usage well. Standardized methods could ensure better comparability between studies of portal use. This study relied on a simple, transparent, and binary composite use variable; however, innumerable different composite variables could be constructed.

\section{Conclusion}

We conducted a subgroup analysis of frequent versus infrequent inpatient portal users from an RCT. The trial provided free technology access and assistance, and subsequently many expected health-equity-related disparities were not observed. However, technology access and assistance did not eliminate disparities based on illness severity and 
preexisting technology experience. Future work should explore strategies, such as enrolling health care proxies and improving usability, to reduce potential disparities in use of inpatient portals.

\section{Multiple Choice Questions}

1. Free technology access and technical assistance may ameliorate which previously identified disparity in inpatient portal use?
a. Age.
b. Technology experience.
c. Illness severity.
d. Insurance status.

Correct Answer: The correct answer option is option a, age. In this study, we found evidence that free technology access and technical assistance may ameliorate disparities in inpatient portal use by age. However, disparities in preexisting technology experience, illness severity, and insurance status remained.

2. Which strategies may ameliorate health-equity-related disparities in patient portal use?

a. Free technology access and technical assistance.

b. Better access policies such as opt-out enrollment.

c. Enrollment of caregivers and health care proxies.

d. All of the above.

Correct Answer: The correct answer is option d, all of the above. In this study, we demonstrate that free technology access and technical assistance ameliorate health-equityrelated disparities in patient portal use. Early evidence also indicates that opt-out enrollment policies, as well as deliberate efforts to engage caregivers, may reduce disparities in use.

\section{Protection of Human and Animal Subjects}

This study was performed in compliance with the World Medical Association Declaration of Helsinki on Ethical Principles for Medical Research Involving Human Subjects, and was reviewed by the Columbia University Medical Center Institutional Review Board.

\section{Funding}

This work was supported by the Agency for Healthcare Research and Quality (R01HS21816, PI: Vawdrey), the National Library of Medicine (T15LM007079), and the National Institute of Nursing Research (K99NR016275, PI: Masterson Creber).

\section{Conflict of Interest}

None declared.

\section{Acknowledgments}

The authors would like to thank Evan Sholle for providing geocoding expertise and code, as well as Abdul Tariq and Raymond Grossman for providing statistical expertise.

\section{References}

1 American Hospital Association. Individuals' ability to electronically access their hospital medical records, perform key tasks is growing. 2016. Available at: http://www.aha.org/ research/reports/tw/16jul-tw-healthIT.pdf. Accessed December 12, 2018

2 Adler-Milstein J, DesRoches CM, Kralovec P, et al. Electronic health record adoption in us hospitals: progress continues, but challenges persist. Health Aff (Millwood) 2015;34(12):2174-2180

3 Adler-Milstein J, DesRoches CM, Furukawa MF, et al. More than half of US hospitals have at least a basic EHR, but stage 2 criteria remain challenging for most. Health Aff (Millwood) 2014;33(09): 1664-1671

4 Charles C, Gafni A, Whelan T. Shared decision-making in the medical encounter: what does it mean? (or it takes at least two to tango). Soc Sci Med 1997;44(05):681-692

5 Berwick DM. Era 3 for medicine and health care. JAMA 2016;315 (13):1329-1330

6 Volpp KG, Mohta NS. Patient engagement survey: far to go to meaningful participation. NEJM Catal; 2016. Available at: http:// catalyst.nejm.org/patient-engagement-initiatives-survey-meaningful-participation/. Accessed December 12, 2018

72014 Edition EHR Certification Criteria Grid Mapped to Meaningful Use Stage 2. Available at: https://www.healthit.gov/sites/ default/files/2014editionehrcertificationcriteria_mustage2.pdf. Accessed December 12, 2018

8 Ancker JS, Silver M, Kaushal R. Rapid growth in use of personal health records in New York, 2012-2013. J Gen Intern Med 2014; 29(06):850-854

9 Undem T. Consumers and health information technology: a national survey. Oakland, CA; 2010. Available at: http://scholar. google.com/scholar?hl=en\&btnG=Search\&q=intitle:Consumers+ and + Health + Information + Technology $+:+\mathrm{A}+$ National+Survey\# 0 . Accessed December 12, 2018

10 Halamka JD, Mandl KD, Tang PC. Early experiences with personal health records. J Am Med Inform Assoc 2008;15(01):1-7

11 Ancker JS, Hafeez B, Kaushal R. Socioeconomic disparities in adoption of personal health records over time. Am J Manag Care 2016;22(08):539-540

12 Patel V, Barker W, Siminerio E. ONC Data Brief No. 30: trends in consumer access and use of electronic health information. 2015. Available at: https://dashboard.healthit.gov/evaluations/databriefs/trends-consumer-access-use-electronic-health-information. php. Accessed December 12, 2018

13 Patel V, Johnson C. ONC Data Brief No. 40: individuals' use of online medical records and technology for health needs. 2017. Available at: https://www.healthit.gov/sites/default/files/page/ 2018-03/HINTS -2017-Consumer-Data-Brief-3.21.18.pdf. Accessed December 12, 2018

14 Collins SA, Rozenblum R, Leung WY, et al. Acute care patient portals: a qualitative study of stakeholder perspectives on current practices. J Am Med Inform Assoc 2017;24(e1):e9-e17

15 Grossman LV, Choi SW, Collins S, et al. Implementation of acute care patient portals: recommendations on utility and use from six early adopters. J Am Med Inform Assoc 2018;25(04):370-379

16 Masterson Creber R, Prey J, Ryan B, et al. Engaging hospitalized patients in clinical care: study protocol for a pragmatic randomized controlled trial. Contemp Clin Trials 2016;47:165-171

17 Runaas L, Hanauer D, Maher M, et al. BMT roadmap: a usercentered design health information technology tool to promote patient-centered care in pediatric hematopoietic cell transplantation. Biol Blood Marrow Transplant 2017;23(05):813-819

18 McAlearney AS, Sieck CJ, Hefner JL, et al. High touch and high tech (HT2) proposal: transforming patient engagement throughout the continuum of care by engaging patients with portal technology at the bedside. JMIR Res Protoc 2016;5(04):e221

19 O'Leary KJ, Lohman ME, Culver E, Killarney A, Randy Smith G Jr, Liebovitz DM. The effect of tablet computers with a mobile patient 
portal application on hospitalized patients' knowledge and activation. J Am Med Inform Assoc 2016;23(01):159-165

20 Winstanley EL, Burtchin M, Zhang Y, et al. Inpatient experiences with MyChart Bedside. Telemed J E Health 2017;23(08): 691-693

21 Prey JE, Restaino S, Vawdrey DK. Providing hospital patients with access to their medical records. AMIA Annu Symp Proc 2014; 2014:1884-1893

22 Vawdrey DK, Wilcox LG, Collins SA, et al. A tablet computer application for patients to participate in their hospital care. AMIA Annu Symp Proc 2011;2011:1428-1435

23 Caligtan CA, Carroll DL, Hurley AC, Gersh-Zaremski R, Dykes PC. Bedside information technology to support patient-centered care. Int J Med Inform 2012;81(07):442-451

24 Kelly MM, Hoonakker PLT, Dean SM. Using an inpatient portal to engage families in pediatric hospital care. J Am Med Inform Assoc 2017;24(01):153-161

25 Larson CO, Nelson EC, Gustafson D, Batalden PB. The relationship between meeting patients' information needs and their satisfaction with hospital care and general health status outcomes. Int J Qual Heal Care 1996;8(05):447-456

26 Skeels M, Tan DS. Identifying opportunities for inpatient-centric technology. Proc ACM IHI 2010:580-589

27 Ancker JS, Barrón Y, Rockoff ML, et al. Use of an electronic patient portal among disadvantaged populations. J Gen Intern Med 2011; 26(10):1117-1123

28 Sarkar U, Karter AJ, Liu JY, et al. The literacy divide: health literacy and the use of an internet-based patient portal in an integrated health system-results from the diabetes study of northern California (DISTANCE). J Health Commun 2010;15(Suppl 2):183-196

29 Yamin CK, Emani S, Williams DH, et al. The digital divide in adoption and use of a personal health record. Arch Intern Med 2011;171(06):568-574

30 Goel MS, Brown TL, Williams A, Cooper AJ, Hasnain-Wynia R, Baker DW. Patient reported barriers to enrolling in a patient portal. J Am Med Inform Assoc 2011;18(Suppl 1):i8-i12

31 Showell C. Barriers to the use of personal health records by patients: a structured review. Peer J 2017;5:e3268

32 Wildenbos GA, Peute L, Jaspers M. Facilitators and barriers of electronic health record patient portal adoption by older adults: a literature study. Stud Health Technol Inform 2017;235:308-312

33 Irizarry T, DeVito Dabbs A, Curran CR. Patient portals and patient engagement: a state of the science review. J Med Internet Res 2015;17(06):e148

34 Robinson JR, Davis SE, Cronin RM, Jackson GP. Use of a patient portal during hospital admissions to surgical services. AMIA Annu Symp Proc 2017;2016:1967-1976

35 Aljabri D, Dumitrascu A, Burton MC, et al. Patient portal adoption and use by hospitalized cancer patients: a retrospective study of its impact on adverse events, utilization, and patient satisfaction. BMC Med Inform Decis Mak 2018;18(01):70

36 Davis SE, Osborn CY, Kripalani S, Goggins KM, Jackson GP. Health literacy, education levels, and patient portal usage during hospitalizations. AMIA Annu Symp Proc 2015;2015:1871-1880

37 Wolff JL, Berger A, Clarke D, et al. Patients, care partners, and shared access to the patient portal: online practices at an integrated health system. J Am Med Inform Assoc 2016;23(06):1150-1158

38 Lober WB, Zierler B, Herbaugh A, et al. Barriers to the use of a personal health record by an elderly population. AMIA Annu Symp Proc 2006;2006:514-518

39 Hilton JF, Barkoff L, Chang O, et al. A cross-sectional study of barriers to personal health record use among patients attending a safety-net clinic. PLoS One 2012;7(02):e31888

40 Butler JM, Carter M, Hayden C, et al. Understanding adoption of a personal health record in rural health care clinics: revealing barriers and facilitators of adoption including attributions about potential patient portal users and self-reported characteristics of early adopting users. AMIA Annu Symp Proc 2013;2013:152-161
41 Veinot TC, Mitchell H, Ancker JS. Good intentions are not enough: how informatics interventions can worsen inequality. J Am Med Inform Assoc 2018;25(08):1080-1088

42 Pew Research Center. 2018 Mobile Fact Sheet. 2018. Available at: http://www.pewinternet.org/fact-sheet/mobile/. Accessed August 20, 2018

43 Pew Research Center. 2018 Internet/Broadband Fact Sheet. 2018. Available at: http://www.pewinternet.org/fact-sheet/internetbroadband/. Accessed July 20, 2018

44 Ancker JS, Nosal S, Hauser D, Way C, Calman N. Access policy and the digital divide in patient access to medical records. Health Policy Technol 2017;6(01):3-11

45 Casey I. The effect of education on portal personal health record use. Online J Nurs Inform 2016;20(02):9

46 McInnes DK, Solomon JL, Shimada SL, et al. Development and evaluation of an internet and personal health record training program for low-income patients with HIV or hepatitis C. Med Care 2013;51(03, Suppl 1):S62-S66

47 Woollen J, Prey J, Wilcox L, et al. Patient experiences using an inpatient personal health record. Appl Clin Inform 2016;7(02): 446-460

48 Masterson Creber RM, Grossman LV, Ryan B, et al. Engaging hospitalized patients with personalized health information: a randomized trial of an acute care patient portal. J Am Med Inform Assoc 2018. Doi: 10.1093/jamia/ocy146

49 Chew LD, Bradley KA, Boyko EJ. Brief questions to identify patients with inadequate health literacy. Fam Med 2004;36 (08):588-594

50 Hibbard JH, Mahoney ER, Stock R, Tusler M. Do increases in patient activation result in improved self-management behaviors? Health Serv Res 2007;42(04):1443-1463

51 Hibbard JH, Greene J. What the evidence shows about patient activation: better health outcomes and care experiences; fewer data on costs. Health Aff (Millwood) 2013;32(02):207-214

52 Hibbard JH, Mahoney ER, Stockard J, Tusler M. Development and testing of a short form of the patient activation measure. Health Serv Res 2005;40(6, Pt 1):1918-1930

53 Hibbard JH. Using systematic measurement to target consumer activation strategies. Med Care Res Rev 2009;66(1, Suppl) 9S-27S

54 Fowles JB, Terry P, Xi M, Hibbard J, Bloom CT, Harvey L. Measuring self-management of patients' and employees' health: further validation of the Patient Activation Measure (PAM) based on its relation to employee characteristics. Patient Educ Couns 2009;77 (01):116-122

55 Greene J, Hibbard JH. Why does patient activation matter? An examination of the relationships between patient activation and health-related outcomes. J Gen Intern Med 2012;27(05): 520-526

56 Hibbard JH, Greene J, Tusler M. Improving the outcomes of disease management by tailoring care to the patient's level of activation. Am J Manag Care 2009;15(06):353-360

57 Prey JE, Qian M, Restaino S, et al. Reliability and validity of the patient activation measure in hospitalized patients. Patient Educ Couns 2016;99(12):2026-2033

58 Bakken S, Grullon-Figueroa L, Izquierdo R, et al; IDEATel Consortium. Development, validation, and use of English and Spanish versions of the telemedicine satisfaction and usefulness questionnaire. J Am Med Inform Assoc 2006;13(06):660-667

59 Horn SD, Horn RA, Sharkey PD. The Severity of Illness Index as a severity adjustment to diagnosis-related groups. Health Care Financ Rev 1984;(Suppl):33-45

60 Averill RF, Goldfield NI, Muldoon J, Steinbeck BA, Grant TM. A closer look at all-patient refined DRGs. J AHIMA 2002;73(01):46-50

61 Charlson ME, Pompei P, Ales KL, MacKenzie CR. A new method of classifying prognostic comorbidity in longitudinal studies: development and validation. J Chronic Dis 1987;40(05): 373-383 
50 Technology Access, Technical Assistance, and Disparities

62 Agency for Toxic Substances and Disease Registry. The Social Vulnerability Index (SVI): SVI Data and Tools Download. 2018. Available at: https://svi.cdc.gov/data-and-tools-download.html. Accessed July 17, 2018

63 Song M-K, Lin F-C, Ward SE, Fine JP. Composite variables: when and how. Nurs Res 2013;62(01):45-49

64 Bursac Z, Gauss CH, Williams DK, Hosmer DW. Purposeful selection of variables in logistic regression. Source Code Biol Med 2008;3:17

65 Calcagno V, De Mazancourt C. glmulti : An R Package for Easy Automated Model Selection with (Generalized) Linear Models. J Stat Softw 2010;34(12):1-29

66 Roblin DW, Houston TK II, Allison JJ, Joski PJ, Becker ER. Disparities in use of a personal health record in a managed care organization. J Am Med Inform Assoc 2009;16(05):683-689

67 Emani S, Yamin CK, Peters E, et al. Patient perceptions of a personal health record: a test of the diffusion of innovation model. J Med Internet Res 2012;14(06):e150

68 Ali SB, Romero J, Morrison K, Hafeez B, Ancker JS. Focus section health IT usability: applying a task-technology fit model to adapt
Grossman et al.

an electronic patient portal for patient work. Appl Clin Inform 2018;9(01):174-184

69 Walker DM, Menser T, Yen P-Y, McAlearney AS. Optimizing the user experience: identifying opportunities to improve use of an inpatient portal. Appl Clin Inform 2018;9(01):105-113

70 Bell SK, Mejilla R, Anselmo M, et al. When doctors share visit notes with patients: a study of patient and doctor perceptions of documentation errors, safety opportunities and the patient-doctor relationship. BMJ Qual Saf 2017;26(04): 262-270

71 Chew S, Brewster L, Tarrant C, Martin G, Armstrong N. Fidelity or flexibility: an ethnographic study of the implementation and use of the Patient Activation Measure. Patient Educ Couns 2018; 101 (05):932-937

72 Ancker JS, Osorio SN, Cheriff A, Cole CL, Silver M, Kaushal R. Patient activation and use of an electronic patient portal. Inform Health Soc Care 2015;40(03):254-266

73 Hibbard JH, Greene J. Who are we reaching through the patient portal: engaging the already engaged? Int J Pers Cent Med 2011;1 (04):788-792 